\title{
Does Botanical Diversity in Sewage Treatment Reed-Bed Sites Enhance Invertebrate Biodiversity?
}

\author{
Alan Feest, ${ }^{1,2}$ Ian Merrill, ${ }^{3}$ and Philippa Aukett ${ }^{1}$ \\ ${ }^{1}$ Water and Environmental Management Research Centre, University of Bristol, 83 Woodland Road, Bristol BS8 1TR, UK \\ ${ }^{2}$ Research and Development Division, Ecosulis Ltd., The Rickyard, Newton St. Loe, Bath BA2 9BT, UK \\ ${ }^{3}$ Severn Trent Water, Endeavour House, Raynesway, Derby DE21 7JA, UK
}

Correspondence should be addressed to Alan Feest, a.feest@bris.ac.uk

Received 16 March 2011; Accepted 1 June 2011

Academic Editor: Madhur Anand

Copyright (C) 2012 Alan Feest et al. This is an open access article distributed under the Creative Commons Attribution License, which permits unrestricted use, distribution, and reproduction in any medium, provided the original work is properly cited.

\begin{abstract}
(1) This study examines the effect of increasing botanical diversity, through reed-bed planting and maintenance regimes, on sewage treatment reed-bed invertebrate biodiversity and the possible enrichment of overall catchment biodiversity. (2) Reedbed invertebrates were identified as a good indicator group of overall site biodiversity quality and were sampled at a range of sewage treatment reed-bed sites in the same geographical area between May and August 2006 (plus one natural reed-bed control site). Standardised water trapping and pitfall trapping techniques were employed throughout this sampling period. (3) Statistical analysis of the sampling results revealed that the number of plant species recorded was inversely related to terrestrial invertebrate species richness, species conservation value index and biomass within the study sites. For example, the natural reed-bed sampled had the highest botanical diversity but the lowest terrestrial invertebrate species richness. (4) This study has demonstrated that sewage treatment reed-beds support a diverse range of invertebrate species, some of them being of national conservation value. This suggests that sewage treatment reed-beds may be at least as biodiverse as naturally occurring reed-beds and will add to the overall biodiversity and ecohydrology of a catchment whilst saving energy.
\end{abstract}

\section{Introduction}

Natural reed-beds have been declining in the UK with an estimated loss of $40 \%$ since 1945 [1]. The UK Government's nature conservation body English Nature [2] recognised that the loss of reed-bed habitat and neglect of remaining reedbeds needed to be addressed. Studies in the UK by the Royal Society for the Protection of Birds [3] have looked initially at ecology and the requirements of high profile reed-bed "flagship" species such as the Great Bittern Botaurus stellaris and Eurasian Marsh Harrier Circus aeruginosus [4, 5].

Reed-bed sewage treatment systems have become increasingly popular especially for small low-maintenance sites. Cooper and Green [6] found that the first systems were in use in 1985, with over 400 systems in the United Kingdom ten years later. The integration of wildlife with commercial uses was studied by Wheeler [7], who stated that, due to the absence of natural reed-beds across much of the UK, artificial reed-beds are of great importance; waste water treatment systems that utilise a mixture of vegetation types can remove pollutants effectively while providing a valuable area for wildlife. In addition they have aesthetic and educational value [8]. If reed-beds are promoted on the basis of their value in water treatment and low energy costs, then catchment water quality and biodiversity could be maintained at a lower carbon cost.

Both the UK Biodiversity Action Plan [9] and a commercial water supply and treatment company's (Severn Trent Water (STW)) own Biodiversity Action Plan [10] identify the importance of the protection and rehabilitation of existing Phragmites australis (Cav.) Trin. ex Steudel reed-beds. STW operates almost 300 reed-beds (Figure 1), covering a total of 10.5 hectares, primarily for the tertiary treatment of wastewater [11]. Invariably these sites are adjacent to river corridors that are, by their nature, conduits for biodiversity. These reed-beds are of potentially significant ecological value on a catchment and national scale and will on occasions represent a major part of minor aquatic flows. It 


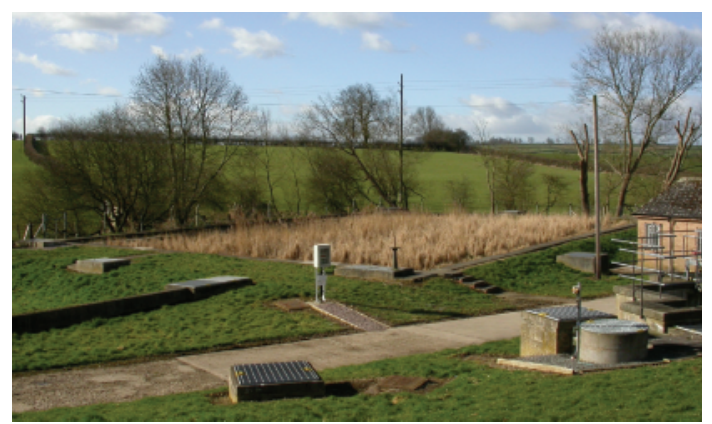

Figure 1: Tertiary treatment reed-bed at Thorpe Satchville Wastewater Treatment Works, Leicestershire Thorpe Satchville, an example of a tertiary treatment reed-bed for wastewater.

is therefore essential that this flow is of high quality, and if this is maintained, the reed-beds will in turn be of added biodiversity value in catchments lacking, or with few, other reed-beds.

For catchments lacking reed-beds whatever biodiversity value sewage treatment reed-beds have will be a supplement to that already extant.

The simplified layout of a typical horizontal flow reedbed, used at all of the sewage treatment survey sites sampled in this study, is illustrated in Figure 2. The P. australis plants are contained within a bed of $5-10 \mathrm{~mm}$ sized clean gravel, laid at an average depth of $0.6 \mathrm{~m}$.

Nuttall et al. [12] state that "Natural wetlands play a vital role in maintaining biological diversity, and this can be strengthened by the contribution from constructed wetlands. The use of constructed wetlands will enhance biodiversity by creating new wetland habitats for animal and plant species." It is the two environmental components, namely, abundant water and growing plants, which provide the essential basis of an ecological food web that results in the presence of wildlife species in all treatment wetlands [13]. Therefore, in wastewater treatment works, the combination of water and plants benefits wildlife [14]. The small size of many of the constructed reed-beds and the artificial nature of environmental variables (high nutrient input water, constant flow unrelated to weather, free draining subsoil, etc.) requires an assessment of the biodiversity value of these new numerous sites compared to the biodiversity of natural sites in the context of a total catchment biodiversity and water quality. There is evidence that constructed wetlands can be at least as good as natural ones in terms of biodiversity [15-18].

Reed-beds are under-studied [19] and, therefore, insights into the relationships between management regime and biodiversity would be of great value. Fojt and Foster [20] identify that treatment reed-beds are often characterised by a dense stand of monodominant reed and, from a botanical point of view, such habitats are of limited interest (except in parts of Great Britain where reed is scarce). They note that, in contrast to the relatively low botanical value of monodominant stands of reed, in nature conservation terms, the invertebrate biodiversity can be of great interest, and therefore there is a poor connection between plant species richness and invertebrate biodiversity. In overall ecohydrological terms the addition of reed-beds therefore adds very little to catchment plant biodiversity but may be of major importance to invertebrate biodiversity especially when the catchment lacks any natural reed-beds as many currently do [1].

For this study, reed-bed invertebrates were identified as a good indicator group due to their habitat-restricted nature. Terrestrial invertebrates were selected in preference to aquatic invertebrates as operational factors invariably lead to an inability to maintain the constant water levels required by such communities, at sewage treatment sites.

Fojt and Foster [20] note that "At least 700 species of invertebrate have been found to be associated with reed-beds in the UK. Some 64 insect species are known to be dependent on reed to some extent, 40 being entirely dependent." Kirby [21] states that all successional stages of a reed-bed support important invertebrate communities and pure stands of wet reed will have lower value in terms of diversity than reedbeds with a drier litter layer. Kirby [21] comments that "vegetation structure is important to invertebrates at every scale" (see also Woodcock et al. [22]). However, studies completed in continental Europe conclude that the total number of invertebrates, species-richness, species diversity, and evenness showed no relationship with management techniques [23-25].

The current lack of appreciation of the terrestrial invertebrate assemblages present in reed-beds [8, 26-28], and ultimately the part that they may play in the wider food webs of this environment, suggests that the role of this habitat in nature conservation terms may not currently be realised to its full potential (e.g., Hawke and Jose [8]).

Fermor and Ireland [29] are pioneers in the study of sewage treatment reed-beds and recommend further study into the invertebrate populations of these habitats. The aim of this study is to investigate the possible link between botanical diversity (number of plant species present), through reed-bed planting and maintenance regimes, and overall reed-bed biodiversity (using numbers of terrestrial invertebrate species as indicators, since in terms of number of species and animal biomass they will be the most significant element), at the selected sewage treatment reed-bed sites. Knight [13] states that as the number of plant species increases in a given area, the habitat diversity for animal species increases due to multiple structural niches as well as the range of food resources available, and therefore we will be testing this assertion.

Results indicating a positive relationship between plant species richness and invertebrate biodiversity could result in a revised water company reed-bed planting and maintenance strategy, and ultimately we would seek to encourage regimes that are proven to maximise overall biodiversity and benefit species groups of recognised ecological importance. The application of management to enhance reed-bed biodiversity would have considerable impact on catchment level biodiversity due to the rarity of the reed-bed habitat.

The research hypotheses therefore are that $\mathrm{H}_{1}$ within sewage treatment reed-beds terrestrial invertebrate biodiversity quality increases with botanical species richness and $\mathrm{H}_{2}$ 


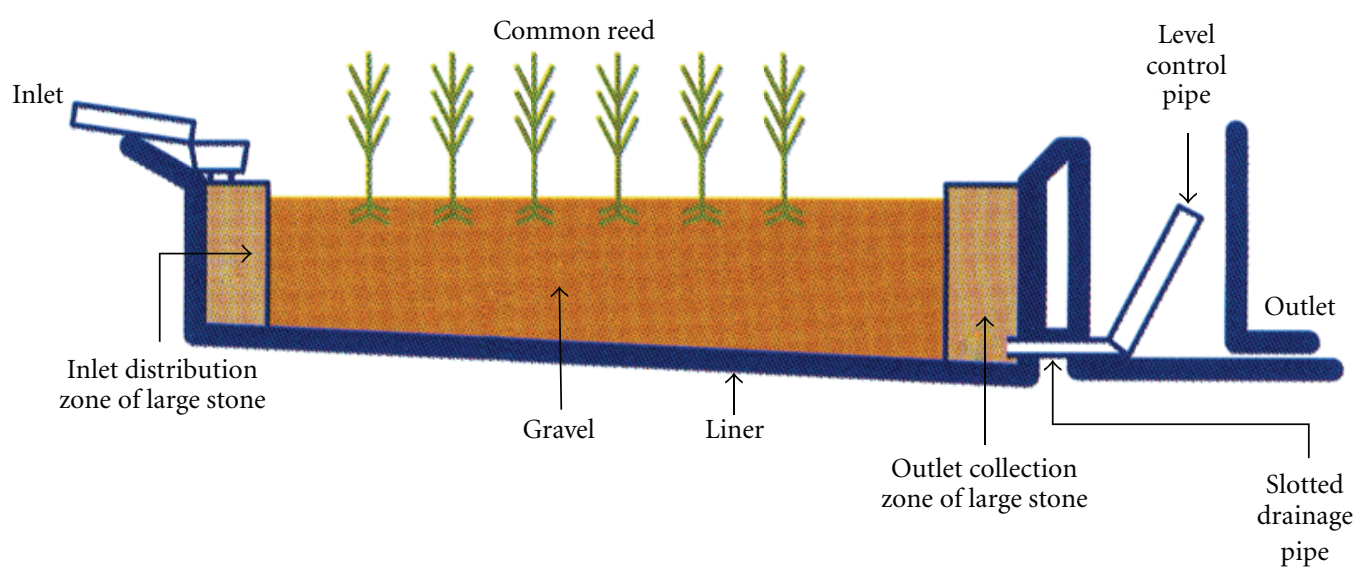

Figure 2: Simplified layout of a tertiary treatment reed-bed shown is the simplified layout of a tertiary treatment reed-bed, where wastewater enters at the inlet, is cleaned in the reed-bed area through filtration and absorption of nutrients by the reeds, and released at the outlet into rivers and streams, hence the location of the reed-bed alongside flowing water. Source is Severn Trent Water [11].

Sewage treatment reed-beds add to the overall catchment biodiversity.

Different sewage treatment reed-bed sites will have different botanical species richness and the terrestrial invertebrate biodiversity quality found at each site is compared against this. Biodiversity quality is defined by Feest et al. [30, 31] as a combination of the number of species (Species Richness) found, the population per unit area, relative proportions of different species either by number or by biomass (ShannonWiener, Simpson, and Berger-Parker Indices), the biomass of these species, and the rarity value (Species Conservation Value Index, SCVI) of species per habitat unit. All of these indices are measurable and therefore possible subjects for statistical analysis. Botanical species richness was defined as the number of individual plant species identified per habitat unit [32].

\section{Materials and Methods}

During 2006 seven sites were chosen for their differing botanical species richness, whilst maintaining a relatively constant size $\left(\mathrm{c} 200-400 \mathrm{~m}^{2}\right)$. The sites were of similar age (c. ten years old) and were within a limited geographical area: two sites of $P$. australis monoculture, two of greatest possible botanical species richness/diversity, two of intermediate diversity, and the natural reed-bed site in the area as a control site. The uniformity of surrounding land use was also considered. All sites chosen were surrounded by arable or pasture land, with those bounding natural wetland areas avoided deliberately. It was considered that species wandering from such sites into the study reed-beds might bias sampling results. Sites for study with their UK grid references are shown in Table 1.

Based on an appraisal of previous studies [8, 33, 34], potentially viable intersite comparators were subsequently measured at each study site. These were average reed height (at the end of the growing season, October/November), reed density (stems per square metre), reed stem thickness (at $0.5 \mathrm{~m}$ above substrate), depth of accumulated plant litter (at

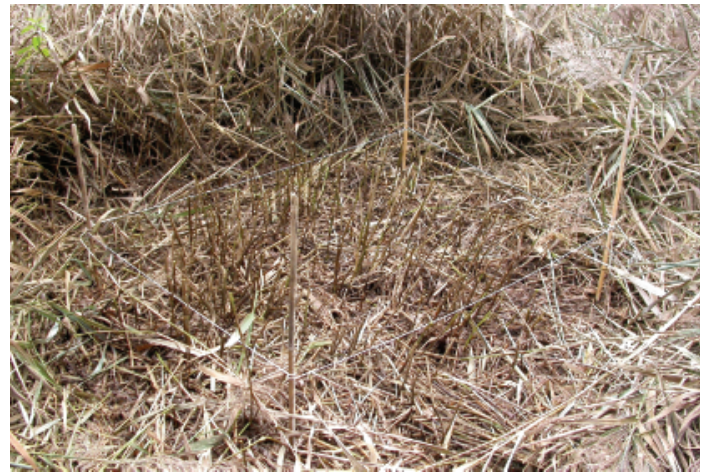

FIGURE 3: Northend STW tertiary treatment reed-bed, Warwickshire, November 2006 illustrating reed density quadrat. A reed density quadrat is shown here as an example of one of the features measured at each reed-bed site. Reed density was found to have a negative effect on invertebrate diversity.

the end of the growing season, October/November), depth of soil above the substrate medium, proportion of bare substrate (by eye, see Figure 3), site area, and reed bed age (from records).

A single botanical survey of each site was undertaken where species abundance was determined for the entire site and included species richness and cover percentage.

Invertebrates were identified to species level wherever possible and species-richness, species diversity, evenness, biomass, and rarity value (SCVI) were calculated $[30,31]$. The diversity and evenness/dominance indices used followed Hill [35].

Pitfall traps were selected for trapping the terrestrial invertebrates as they are effective in sampling active, surfaceliving invertebrates in low vegetation and bare ground, particularly Hymenoptera (ants), Hemiptera (true bugs), Coleoptera (beetles), and Araneae (spiders) [36].

Plastic pitfall traps $85 \mathrm{~mm}$ deep by $60 \mathrm{~mm}$ in diameter were set in the gravel substrate of the reed-bed with the rim 
TABLE 1: Schedule of tertiary treatment and natural reed-bed sites selected for study references for the locations of chosen reed-bed field sites for the invertebrate and botanical diversity study, with features such as elevation and size of sites.

\begin{tabular}{|c|c|c|c|c|}
\hline Site & County & Ordnance survey grid reference & Elevation (m) & Size $\left(\mathrm{m}^{2}\right)$ \\
\hline Ragdale & Leicestershire & SK 684196 & 95 & 412 \\
\hline Thorpe Satchville & Leicestershire & SK 730108 & 110 & 285 \\
\hline Waltham on the Wolds & Leicestershire & SK 793256 & 135 & 370 \\
\hline Priors Hardwick & Warwickshire & SP 466762 & 120 & 183 \\
\hline Northend & Warwickshire & SP 389529 & 100 & 294 \\
\hline Lighthorne Heath & Warwickshire & SP 360565 & 120 & 246 \\
\hline Brandon Marsh* & Warwickshire & SP 385757 & 70 & 30,000 \\
\hline
\end{tabular}

${ }^{*}$ Natural reed-bed.

flush with ground level. Three traps were set at each reedbed study site, in a straight line $0.5 \mathrm{~m}$ apart in the geographic centre of the reed-bed. Once installed, the pitfall traps were filled with a small amount of killing agent/preservative in the form of commercial antifreeze ( $95 \%$ ethylene glycol). These were emptied and reset at monthly intervals. The contents of each set of three pitfall traps were preserved in $70 \%$ ethanol for future identification.

Water traps were used to trap flying insects, mainly Diptera (true-flies) and Hymenoptera (bees, ants, and wasps). Two identical yellow bowls [36] were placed at each survey site, measuring approximately $200 \mathrm{~mm} \times 120 \mathrm{~mm}$ in area and positioned $0.5 \mathrm{~m}$ apart in the geographic centre of each reed-bed. Each bowl was filled with a small amount of water and detergent [36] and emptied 48 hours after setting. The contents of each set of two water traps were preserved in ethanol for future study.

The analysis related to this study involves comparison of the data sets gathered at the various survey sites and the use of the "Fungib" software $([30,31]$ available as a free download from ecosulis ltd.) quickly produces measured biodiversity indices for use in site comparisons. Further data investigations were completed via principle component analysis, which allows analysis of the relationships between the different indices. In particular, similarities and differences are demonstrated when the results are plotted graphically [37].

Biodiversity analyses were completed by developing a species value ranking and a biomass ranking for each individual species. For a species value index (SCVI), a ranking system was applied based on UK data taken from the National Biodiversity Network (NBN) Gateway website (NBN, 2007) as follows: present in $1000+10 \mathrm{~km}$ grid squares $=2$; $501-1000=3 ; 201-500=4 ; 51-200=5 ; 11-50=10 ; 1-10=$ 20; Red Data Book2/Nationally scarce $B=100$. A biomass ranking system was applied to each species recorded. All of the invertebrates sampled fell within a restricted size range; so the biomass ranking system simply used the body length in millimetres of each species. Where a range of size was given, a mean value was used. Length is considered to be a good indicator of relative mass in this instance, as all species had a similar structural shape $[38,39]$.
2.1. Botanical Sampling Methodology. The limited botanical diversity encountered at the study sites required the use of a full site survey rather than a quadrat methodology (many quadrats would have contained only one species!). The number of species and cover of each species were recorded. Sutherland [36] defines cover as a "size-based measure of the area covered by the above ground parts of a species when viewed from above". A single botanical survey at the time of the year with the highest ground cover (17-18 July) was conducted using visual estimation.

2.2. Statistical Analysis. Since there was expected to be an element of linkage of the measured factors, Principle Component Analysis (PCA) was used for analysis since it is less susceptible to linkages [37]. Much of the data was nonnormally distributed which PCA also copes with [37]. A Principle Component Analysis (PCA) was carried out, using statistical analysis software (StatistiXL, [40]), considering the reed-bed site-specific variables.

\section{Results}

A total of 255 invertebrates were identified to species level from the samples taken and an example of the treatment of the data to produce (a) SCVI scores and (b) biomass indices applied to part of the Coleoptera samples is given in Table 2.

The diagrammatic outputs of the PCA are given in Figures 4, 5, and 6 with summarised data tables shown in Appendix II in the Supplementary Material that appears online at doi:10.1155/2012/324295.

Figures 4-6 show a statistical analysis of invertebrate species richness, SCVI, and biomass compared with all the site-specific variables measured. Bare substrate is the only variable to positively relate to all three, and even this is a loose relationship where $76.1 \%, 73.2 \%$, and $78.4 \%$ of the components are either inversely related to, or do not relate to, species richness, SCVI, or Biomass.

"Soil" depth (accumulated organic solids), age of reedbed, area of reed-bed, and plant species diversity are all inversely related to the biodiversity indices being investigated and shown in Figures 4-6. 
TABle 2: Example of species value and biomass ranking applied to part of the coleoptera sample data. Calculation of species value and biomass ranking was completed for all invertebrate species collected, of which a sample of the Coleoptera is shown here. This data was then used to ascertain the diversity of the reed-bed sites.

\begin{tabular}{|c|c|c|c|c|c|}
\hline Order & Taxon & Total no. rec. & Total UK 10 km grid squares* & Total UK ranking value & Biomass (length in $\mathrm{mm}$ ) \\
\hline \multirow{8}{*}{ Coleoptera } & Pterostichus niger & 14 & 930 & 3 & 17.5 \\
\hline & Pterostichus nigrita & 19 & 40 & 10 & 12.5 \\
\hline & Pterostichus strenuus & 10 & 994 & 3 & 6.0 \\
\hline & Pterostichus vernalis & 2 & 457 & 4 & 6.8 \\
\hline & Stenolophus mixtus & 1 & 257 & 4 & 5.3 \\
\hline & Altica lythri & 8 & 79 & 5 & 5.0 \\
\hline & Aphthona euphorbiae & 2 & 98 & 5 & 4.0 \\
\hline & Chaetocnema hortensis & 11 & 35 & 10 & 1.9 \\
\hline
\end{tabular}

* Source data NBN Gateway, correct as of 30/03/07.

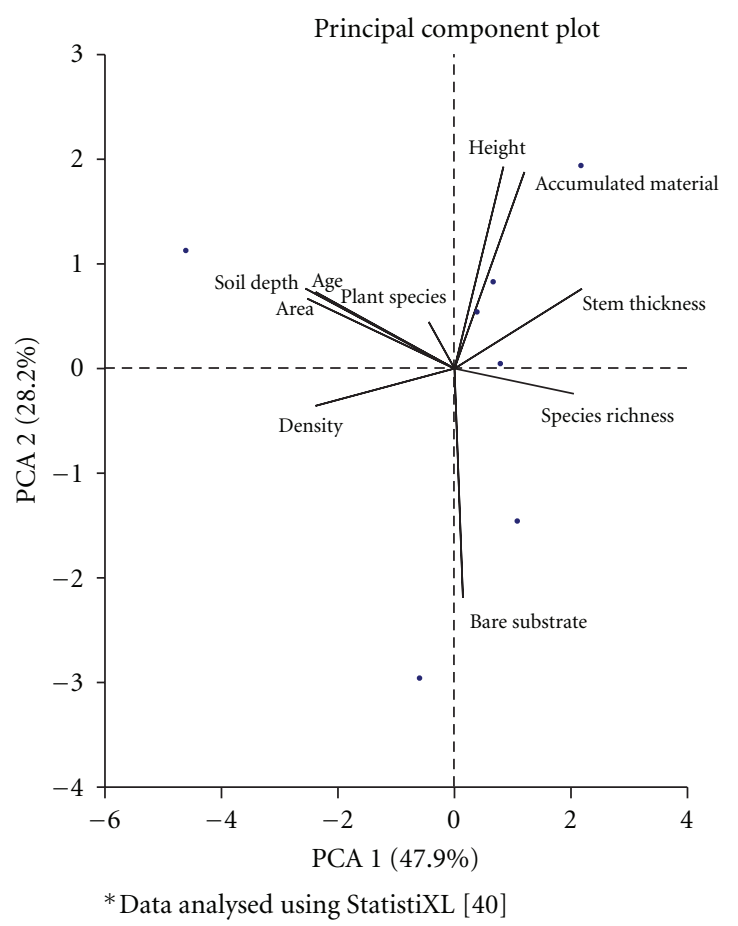

Figure 4: PCA* of Species Richness against all other SiteSpecific Variables. From this PCA analysis of species richness of invertebrates across all reed-bed sites, only bare substrate was found to be positively correlated, whilst age, area, soil depth, and plant species richness were found to be negatively correlated. All other variables measured did not affect species richness.

\section{Discussion}

Priors Hardwick, the site with the greatest botanical diversity at 19 plant species, has the second lowest invertebrate species richness and the lowest species value index (see Table 3 ). The site with the highest invertebrate species richness and species value index, Thorpe Satchville, has the second highest botanical diversity at 17 species. There is, however, no further correlation amongst the remainder of the site rankings. Brandon Marsh Nature Reserve, selected as a baseline natural reed-bed site, produces consistently lower scores in terms of biodiversity rankings than the sewage reed-bed sites.

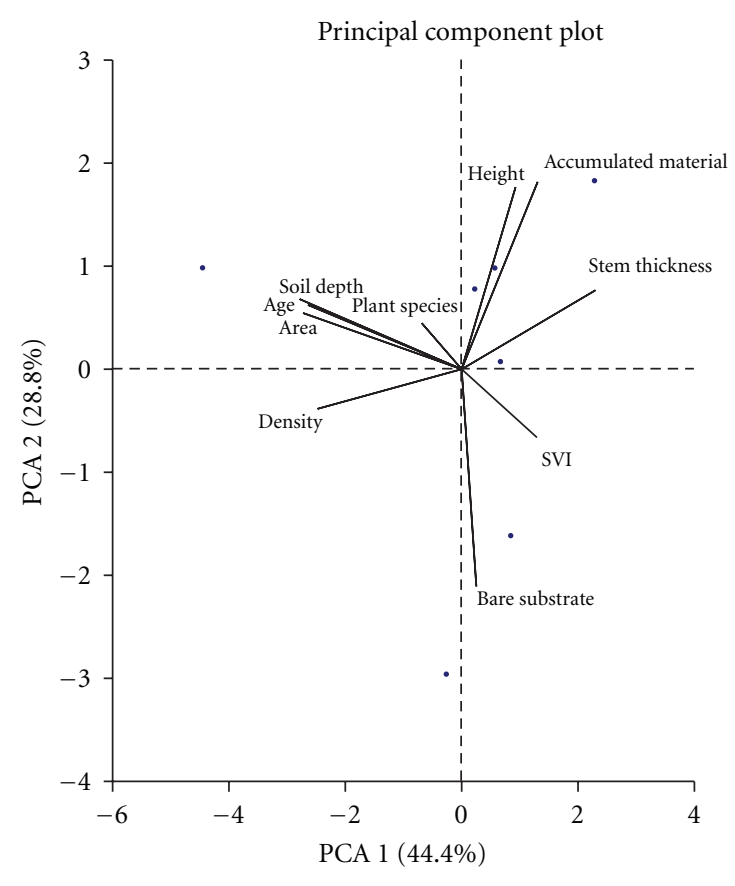

Figure 5: PCA* of SCVI against all other Site-Specific Variables. From the PCA Analysis of Species Value Index of invertebrates across all reed-bed sites, only bare substrate was found to be positively correlated, whilst age, area, soil depth, and plant species richness were found to be negatively correlated. All other variables measured did not affect species richness.

Therefore, the findings of the study do not support the research hypothesis $\left(\mathrm{H}_{1}\right)$, that sewage treatment reed-bed botanical diversity is positively linked to reed-bed terrestrial invertebrate biodiversity quality. This conclusion contradicts the work of Knight [13] who stated that faunal diversity is directly related to plant community diversity and that plant monocultures can result in relatively low animal diversities.

When considering these findings, it is worth noting that the botanical species other than $P$. australis actually occupy a very small proportion of the total reed-bed area. With the exception of two study sites, all reed-beds were comprised of 
TABLE 3: Summary of "Fungib" invertebrate outputs and plant species recorded at each site. Invertebrate data for each reed-bed site has produced outputs from the computer programme "Fungib." Highest scores are shown in bold and lowest in italic. It is immediately obvious that in reed-beds, plant species richness does not correlate with invertebrate species richness.

\begin{tabular}{lcccc}
\hline Site & Plant species & Invertebrate species richness & Invertebrate SVI & Invertebrate biomass \\
\hline Priors Hardwick & $\mathbf{1 9}$ & 71 & 6.1830 & 1794.0 \\
Thorpe Satchville & 17 & $\mathbf{1 1 2}$ & $\mathbf{1 0 . 1 1 6 0}$ & 4461.0 \\
Brandon Marsh NR & 14 & 51 & 6.9607 & 825.0 \\
Northend & 10 & 76 & 6.7763 & 2512.0 \\
Lighthorne Heath & 8 & 89 & 8.0000 & 3612.0 \\
Ragdale & 7 & 88 & 8.9772 & 4797.0 \\
Waltham & 4 & 63 & 7.6666 & $\mathbf{5 1 4 1 . 2}$ \\
\hline
\end{tabular}

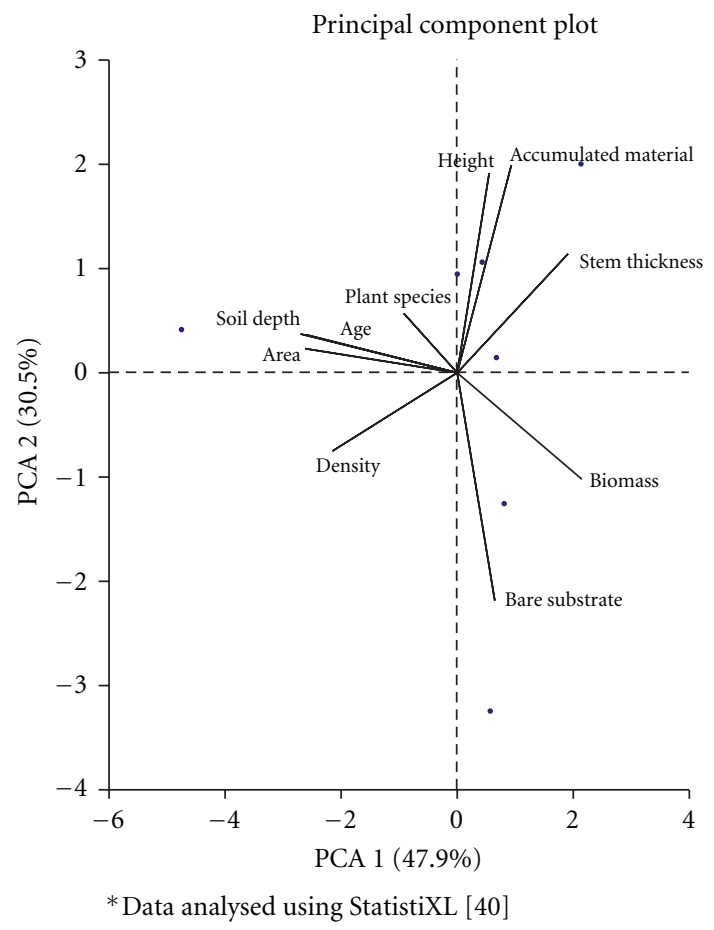

Figure 6: PCA* of Biomass against all other Site-Specific Variables. From the PCA of Biomass of invertebrates across all reed-bed across all reed-bed sites, only bare substrate was found to be positively correlated, whilst age, area, soil depth, and plant species richness were found to be negatively correlated. All other variables measured did not affect species richness.

95\% ground cover of $P$. australis, and therefore the influence that other botanical species could have on invertebrate populations may be expected to be relatively insignificant. A full list of botanical species recorded and proportions of the site occupied is found in Appendix I in the Supplementary Material that appears online at doi:10.1155/2012/324295. It was apparent that the vigorously growing $P$. australis plants rapidly smothered all other species, allowing minimal botanical diversity in any of the reed-beds surveyed. This applied to both natural and sewage treatment reed-beds.
Manios et al. [18] refer to a similar effect in sewage treatment plots growing Arundo donax, the giant reed.

The principal component plots clearly indicate that the number of plant species recorded is inversely related to invertebrate species richness, species value index, and biomass within the study sites. For example, Waltham-onthe-Wolds has the highest biomass score but also the lowest botanical diversity. Saint-Germain et al. [41] note that data sets produced using pitfall trapping are likely to show strong abundance to biomass correlations, in particular when considering generalist predators such as ground beetles. Saint-Germain et al. [41] also consider that in biodiversity assessments, biomass is a much neglected component since it has an important ecosystem effect (energy and materials).

Bare substrate present within the reed-bed was found to have a positive influence on levels of invertebrate diversity (so the barer the substrate in the reed-bed, the more and rarer the invertebrates). All other measured site-specific variables appear to have either an inverse relationship with invertebrate diversity or have no directly discernable link at all. It must therefore be considered that the presence of bare substrate, its microhabitats, and its associated mosaic vegetation are of considerable importance in promoting optimum treatment reed-bed diversity. It could be considered that a barer substrate would open up the habitat to ease the movement of active invertebrates such as ground beetles, but the data from water-traps means that we have to consider free-flying invertebrates as well. Bare substrate may indicate less flight obstruction for these free-flying invertebrates and better visibility of the traps [42-44]. Whatever the mechanism, the effect is confirmed for three of the biodiversity quality measures (Biomass, Species Richness, and SCVI). Reed-beds and similar nutrient rich wet sites have been shown to have an abundance of Collembola and soil mites (as well as earthworms and carabids) [45-47] and therefore would be rich in prey for carnivorous invertebrates.

It is possible that a smaller reed-bed, possessing more "edge" habitat and thus greater habitat diversity, may be expected to support a more varied invertebrate population. In the course of the survey work, it was apparent that many of the plant species were concentrated around this reed-bed edge habitat, supporting this theory (see also Manios et al., [18] for a similar effect with Arundo donax). Additionally, 
principal component plots showed that increased reedbed area has a negative effect on terrestrial invertebrate diversity. So on a management level, it should be noted that even the smallest reed-beds are of value in terms of their biodiversity and will contribute to the natural environment, especially in areas where natural reed-bed habitat is at a premium.

A recent study of invertebrate assemblages within improved grassland by Woodcock et al. [22] provides an interesting parallel with these findings. Woodcock et al.'s study concludes that sward complexity is an important determinant of predatory invertebrate species richness (sward complexity could be considered comparable to the mosaic vegetation influence within treatment reed-beds). Also of relevance to this study is Woodcock et al.'s conclusion that for phytophagous invertebrates, diversity was not positively linked to plant community assemblage. In fact, the study concluded that for phytophagous true bugs, plant community assemblage was inversely proportional to species richness. This mirrors the findings of this study.

For Hypothesis $\mathrm{H}_{2}$ it has been found that not only do sewage treatment reed-beds add to catchment ecohydrological quality in terms of added species but also on occasions the added biodiversity is of higher value than is the case for natural reed-beds. Since the treatment reed-beds function on a lower-energy basis and have to comply with discharge values, this biodiversity increment is achieved at no loss of water quality. This can be an important factor when the treatment reed-bed discharge contributes significantly to a small flow stream.

As reed-bed age does not appear to affect biodiversity adversely, the water company's 300 reed-beds should be viewed as a permanent asset and not one that varies in ecological value on a sliding scale, related to time since refurbishment; it may even be the case that such refurbishment works and the creation of a new reed-bed habitat encourages a range of early successional species which may be of greater ecological significance than those which are replaced. Balcombe et al. [15-17] demonstrate clearly that mitigation wetlands are of a value at least equal to that of natural sites for both plant and animal biodiversity. The combination of enhanced biodiversity value with the sewage treatment facility (especially phosphorus removal) could be strong arguments for further use of reed-beds within catchments and a consequent increase in value of the overall catchment ecohydology.

One of the more unexpected findings of the study has been the relatively poor performance of the natural reedbed site at Brandon Marsh Nature Reserve, in terms of species richness, species value, and biomass, when compared with the sewage treatment sites. A possible reason for this trend could be the greater availability of "food" (i.e., treated effluent) at the foot of the food chain within the treatment reed-beds. The constant supply of both moisture and potential food items may have a positive effect through the various trophic levels within the reed-bed invertebrate community. Another possible explanation for this lower biodiversity in a natural reed-bed might be the timing of the sampling since these is evidence that reed-bed invertebrate biodiversity is greater in the winter [48-50].

Although the biomass score (in which Brandon occupies the lowest position) supports this theory, further investigations into trophic relationships produce less clear-cut results. Within the Coleoptera, for example, predominantly predatory species, such as those found in the Carabidae and Staphylinidae families, are distributed equally amongst sewage treatment reed-beds and the natural reed-bed site. Similarly the phytophagous family Chrysomelidae occurs in similar numbers at both types of reed-bed; one might have expected differing distributions of predatory and phytophagous invertebrates between reed-bed types. The biodiversity of natural reed-beds seems to be very variable as it responds to changing physicochemical conditions [48-50].

Another possible reason for the differing biodiversity rankings is the comparability of the levels of succession within the natural and sewage treatment sites. In order to utilize the chosen water-trapping and pitfall trapping methodologies at Brandon, a marginal area of reed-bed was selected, as the main reed-bed was standing in several centimetres of water; the chosen trapping techniques would not have been possible in areas of standing water, where clearly aquatic invertebrates would predominate. The natural reedbed sampling site could feasibly be described as successional habitat rather than true reed-bed, although treatment reedbeds of all ages may actually be viewed as pseudosuccessional habitat suspended permanently at a late successional stage. The varying water levels found on the margin of this site will perhaps have reduced invertebrate biodiversity quality, since the periodic inundation and drying will eliminate those species requiring either wet or dry conditions and therefore the margin will need periodic colonisation [51]. In terms of overall catchment ecohydrological processes the suspended succession will, in a contradictory way, provide long-term ecological niches (through active reedbed maintenance for effectiveness of treatment and discharge standard) for successional invertebrates that naturally would have a restricted colonization opportunity.

The data collected in the course of this study has demonstrated that sewage treatment reed-beds support a diverse range of invertebrate species, some of them being of national conservation value. It has also shown that terrestrial invertebrate diversity at sewage treatment reed-beds can be equivalent to, if not greater than, that at natural $P$. australis reed-bed sites. These findings concur with previous work by Wheeler [7], Hawke and Jose [8], and Worrall et al. [14], all of whom stressed the great ecological importance of sewage treatment reed-beds.

The current promotion of Sustainable Urban Drainage Systems (SUDS) will in many cases result in the provision of water bodies with reed-beds and it is possible that these as well as having a hydrological function will provide opportunities for enhanced biodiversity. Whether this will relate more to natural reed-beds or sewage treatment reedbeds will be an interesting investigation since SUDS sites will often have varying water levels over the course of a year. They will respond to the urban drainage characteristics and 
increased occurrence of extreme rainfall events as modelled by GCC scientists [52].

The incidence of a large number of invertebrate species associated with wetland habitats within the subsurface flow tertiary treatment reed-beds suggests that they are functioning as pseudowetlands in their own right. As such, these reed-beds should be seen as of considerable ecological value, especially in light of the decrease in natural reed-beds in recent times [1]. The enhanced ecological value of these reedbeds should be at no loss of water quality especially as water companies have to aim for "good ecological status" under the EU Water Framework Directive [53]. Treatment reedbeds can therefore support this aim and add to catchment water quality and biodiversity. This should encourage water companies to adopt the technology as part of their range of sewage treatment options allowing them to emphasize the resulting improvement of the catchment ecohydrology.

To achieve such a shift in wastewater treatment process design culture would require extensive adoption by water companies, but the advantages could be considerable if applied on a national scale. Reduced aesthetic and overall environmental impact greatly decreased energy demands and biodiversity benefits would all result.

\section{Acknowledgments}

Thanks are given to Dr. Philip Fermor, Lee Miles, and Richard Wright of Middlemarch Environmental for help with methodology, collection, and identification; also Paul Griffin, Andrew Warren, Ian Gray, Nigel McGuinness, Michael Lomas, and Michael Fairlamb of Severn Trent Water for their funding, support, and insights; additionally, Warwickshire Wildlife Trust for giving access to their natural reed-bed for a control site; Andrew Brewer of the National Biodiversity Network Gateway for help with the analysis; and Victoria Bodycote for personal support. The authors also thank two referees for their detailed and helpful comments on a first draft. A. Feest is employed by Ecosulis Ltd., and the University of Bristol, http://www.ecosulis.co.uk/.

\section{References}

[1] C. Bibby, S. Housden, R. Porter, and G. Thomas, A Conservation Strategy for Birds, RSPB, Bedfordshire, UK, 1989.

[2] English Nature, Action for Reedbed Birds in England, EN Action Plan, Peterborough, UK, 1994.

[3] M. Painter, The UK Reed-Bed Inventory Report, RSPB, Bedfordshire, UK, 1994.

[4] J. Andrews and D. Ward, "The management and creation of reed-beds, especially for rare birds," British Wildlife, vol. 3, no. 2, pp. 81-91, 1991.

[5] G. Tyler, "Requirements of birds in reed-beds," in Reed-Beds for Wildlife, D. Ward, Ed., p. 100, RSPB/University of Bristol, Bristol, UK, 1992.

[6] P. F. Cooper and M. B. Green, "Reed-bed treatment systems for sewage treatment in the United Kingdom-the first 10 years experience," Water Science and Technology, vol. 32, no. 3, pp. 317-327, 1995.
[7] B. D. Wheeler, "Integrating wildlife with commercial uses," in Reed-Beds for Wildlife, D. Ward, Ed., pp. 79-89, RSPB/University of Bristol, Bristol,UK, 1992.

[8] C. J. Hawke and P. V. Jose, Reed-Bed Management for Commercial and Wildlife Interests, RSPB, Bedfordshire, UK, 1996.

[9] Joint Nature Conservation Committee, Biodiversity: The UK Action Plan, JNCC, Peterborough, UK, 1994.

[10] Severn Trent Water, Biodiversity Action Plan, Severn Trent Water, Birmingham, UK, 1999.

[11] A. Warren, Streamline: Wildlife Watch October, Severn Trent Water Plc, Birmingham, UK, 2005.

[12] P. M. Nuttall, A. G. Boon, and M. R. Rowell, "Review of the design and management of constructed wetlands," CIRIA Report 180, Construction Industry Research and Information Association, London, UK, 1997.

[13] R. L. Knight, "Wildlife habitat and public use benefits of treatment wetlands," Water Science and Technology, vol. 35, no. 5, pp. 35-43, 1997.

[14] P. Worrall, K. J. Peberdy, and M. C. Millett, "Constructed wetlands and nature conservation," Water Science and Technology, vol. 35, no. 5, pp. 205-213, 1997.

[15] C. K. Balcombe, J. T. Anderson, R. H. Fortney, and W. S. Kordek, "Aquatic macroinvertebrate assemblages in mitigated and natural wetlands," Hydrobiologia, vol. 541, no. 1, pp. 175$188,2005$.

[16] C. K. Balcombe, J. T. Anderson, R. H. Fortney, and W. S. Kordek, "Wildlife use of mitigation and reference wetlands in West Virginia," Ecological Engineering, vol. 25, no. 1, pp. 85-99, 2005.

[17] C. K. Balcombe, J. T. Anderson, R. H. Fortney, J. S. Rentch, W. N. Grafton, and W. S. Kordek, "A comparison of plant communities in mitigation and reference wetlands in the midappalachians," Wetlands, vol. 25, no. 1, pp. 130-142, 2005.

[18] T. K. Manios, Z. Kypriotakis, V. Manios, and G. Dialyna, "Plant species in a two-year-old free water surface constructed wetland treating domestic wastewater in the island of Crete," Journal of Environmental Science and Health, vol. 37, no. 7, part A37, pp. 1327-1335, 2002.

[19] D. Ward, "Management of reedbeds for wildlife," in ReedBeds for Wildlife, D. Ward, Ed., pp. 65-78, RSPB/University of Bristol, Bristol, UK, 1992.

[20] W. Fojt and A. Foster, "Reed-beds, their wildlife and requirements A. Botanical and invertebrate aspects of reedbeds, their ecological requirements and conservation significance," in Reed-Beds for Wildlife, D. Ward, Ed., pp. 49-56, RSPB/University of Bristol, Bristol, UK, 1992.

[21] P. Kirby, Habitat Management for Invertebrates: A Practical Handbook, RSPB, Bedfordshire, UK, 1992.

[22] B. A. Woodcock, S. G. Potts, D. B. Westbury et al., "The importance of sward architectural complexity in structuring predatory and phytophagous invertebrate assemblages," Ecological Entomology, vol. 32, no. 3, pp. 302-311, 2007.

[23] M. K. M. Ditlhogo, R. James, B. R. Laurence, and W. J. Sutherland, "The effects of conservation management of reed beds. I. The invertebrates," Journal of Applied Ecology, vol. 29, no. 2, pp. 265-276, 1992.

[24] J. H. Mook, "Influence of environment on some insects attacking common reed (phragmites communis trin.)," Hydrobiologia, vol. 12, pp. 305-312, 1971.

[25] V. Skuhravy, "Invertebrates: destroyers of common reed," in Pond Littoral Ecosystems-Structure and Functioning, D. Dykjova and J. Kvet, Eds., vol. 28 of Ecological Studies, pp. 376378, Springer, New York, NY, USA, 1978. 
[26] A. P. Bedford and I. Powell, "Long-term changes in the invertebrates associated with the litter of Phragmites australis in a managed reedbed," Hydrobiologia, vol. 549, no. 1, pp. 267285, 2005.

[27] H. A. Neckles, H. R. Murkin, and J. A. Cooper, "Influences of seasonal flooding on macroinvertebrate abundance in wetland habitats," Freshwater Biology, vol. 23, no. 2, pp. 311-322, 1990.

[28] S. A. Wissinger, "Ecology of wetland invertebrates, synthesis and applications for conservation management," in Invertebrates in Freshwater Wetlands of North America: Ecology and Management, D. P. Batzer, R. B. Rader, and S. A. Wissenger, Eds., pp. 1043-1086, John Wiley \& Sons, New York, NY, USA, 1999.

[29] P. Fermor and S. Ireland, Biodiversity Enhancement of Severn Trent Water Reedbed Treatment Systems. Shipston Fell Mill Invertebrate Survey, Middlemarch Environmental, Warwickshire, UK, 2001.

[30] A. Feest, "Establishing baseline indices for the quality of the biodiversity of restored habitats using a standardized sampling process," Restoration Ecology, vol. 14, no. 1, pp. 112-122, 2006.

[31] A. Feest, T. D. Aldred, and K. Jedamzik, "Biodiversity quality: a paradigm for biodiversity," Ecological Indicators, vol. 10, no. 6, pp. 1077-1082, 2010.

[32] C. P. Wheater and P. A. Cook, Studying Invertebrates, vol. 28 of Naturalists' Handbooks, Richmond Publishing, Slough, UK, 2003.

[33] R. R. Boar, Factors Which Affect the Growth of Phragmites Australis, University of East Anglia, Norwich, UK, 1991.

[34] N. R. Cowie, W. J. Sutherland, M. K. M. Ditlhogo, and R. James, "The effects of conservation management of reed beds. II. The flora and litter disappearance," Journal of Applied Ecology, vol. 29, no. 2, pp. 277-284, 1992.

[35] M. O. Hill, "Diversity and evenness: a unifying notation and its consequences," Ecology, vol. 54, no. 2, pp. 427-432, 1973.

[36] W. J. Sutherland, Ecological Census Techniques: A Handbook, Cambridge University Press, Cambridge, UK, 2nd edition, 2006.

[37] P. A. Henderson and R. M. H. Seaby, A Practical Handbook for Multivariate Methods, Pisces Conservation, Lymington. UK, 2008.

[38] C. J. Brady and R. A. Noske, "Generalised regressions provide good estimates of insect and spider biomass in the monsoonal tropics of Australia," Australian Journal of Entomology, vol. 45, no. 3, pp. 187-191, 2006.

[39] B. E. Sample, R. J. Cooper, R. D. Greer, and R. C. Whitmore, "Estimation of insect biomass by length and width," American Midland Naturalist, vol. 129, no. 2, pp. 234-240, 1993.

[40] StatistiXL, 2007, http://www.statistixl.com/.

[41] M. Saint-Germain, C. M. Buddle, M. Larrivée et al., "Should biomass be considered more frequently as a currency in terrestrial arthropod community analyses?" Journal of Applied Ecology, vol. 44, no. 2, pp. 330-339, 2007.

[42] A. Spalding and H. C. Haes, "Contaminated land-a resource for wild life: a review and survey of insects on metalliferous sites in Cornwall," Land Contamination and Reclamation, vol. 3, pp. 25-29, 1995.

[43] C. A. Harvey, A. Medina, D. M. Sánchez et al., "Patterns of animal diversity in different forms of tree cover in agricultural landscapes," Ecological Applications, vol. 16, no. 5, pp. 19861999, 2006.

[44] J. Babin-Fenske and M. Anand, "Terrestrial insect communities and the restoration of an industrially perturbed landscape: assessing success and surrogacy," Restoration Ecology, vol. 18, no. 1, pp. $73-84,2010$.
[45] B. Lübben, "Influence of sewage sludge and heavy metals on the abundance of Collembola on two agricultural soils," in Proceedings of the 3rd International Seminar on Apterygota, R. Dallai, Ed., pp. 419-428, University of Siena, Siena, Italy, 1989.

[46] D. Pimental and A. Warneke, "Ecological effects of manure, sewage sludge and other organic wastes on arthropod populations," Agricultural Zoology Reviews, vol. 3, pp. 1-30, 1989.

[47] C. Pernin, J.-P. Ambrosi, J. Cortet et al., "Effects of sewage sludge and copper enrichment on both soil mesofauna community and decomposition of oak leaves (Quercus suber) in a mesocosm," Biology and Fertility of Soils, vol. 43, no. 1, pp. 39-50, 2006.

[48] J. M. C. K. Jayawardana, M. Westbrooke, M. Wilson, and C. Hurst, "Macroinvertebrate communities in willow (Salix spp.) and reed beds (Phragmites australis) in central victorian streams in Australia," Marine and Freshwater Research, vol. 57, no. 4, pp. 429-439, 2006.

[49] J. M. C. K. Jayawardana, M. Westbrooke, M. Wilson, and C. Hurst, "Macroinvertebrate communities in Phragmites australis (Cav.) trin. ex steud. reed beds and open bank habitats in central victorian streams in Australia," Hydrobiologia, vol. 568, no. 1, pp. 169-185, 2006.

[50] J. Sychra, Z. Adámek, and K. Petřivalská, "Distribution and diversity of littoral macroinvertebrates within extensive reed beds of a lowland pond," International Journal of Limnology, vol. 46, no. 4, pp. 281-289, 2010.

[51] I. Varga, "Macroinvertebrates in reed litter," International Review of Hydrobiology, vol. 86, no. 4-5, pp. 573-583, 2001.

[52] B. C. Bates, Z. W. Kundewicz, S. Wu, and J. P. Palutikof, "Climate change and water," Tech. Rep., The Intergovernmental Panel on Climate Change, IPCC Secretariat, Geneva, Switzerland, 2008, http://www.ipcc.ch/pdf/technical-papers/ climate-change-water-en.pdf.

[53] European Community, "Directive 2000/60/EC establishing a framework for Community action in the field of water policy," Official Journal of the European Communities, vol. 22, no. 12, p. 2000, 2000. 

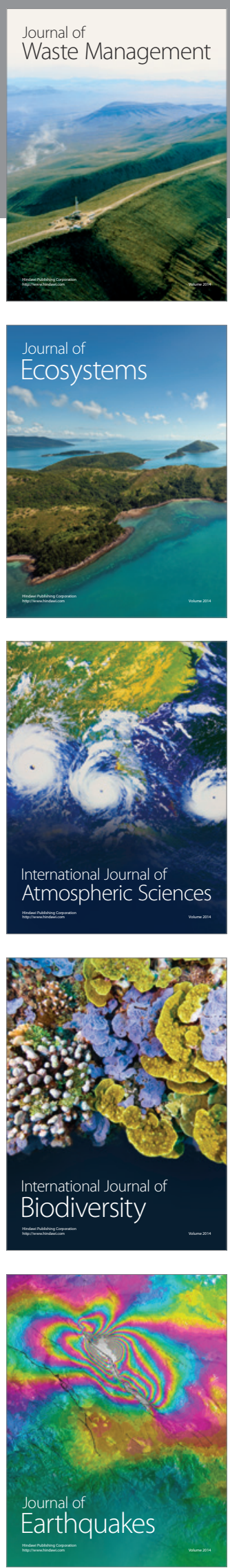
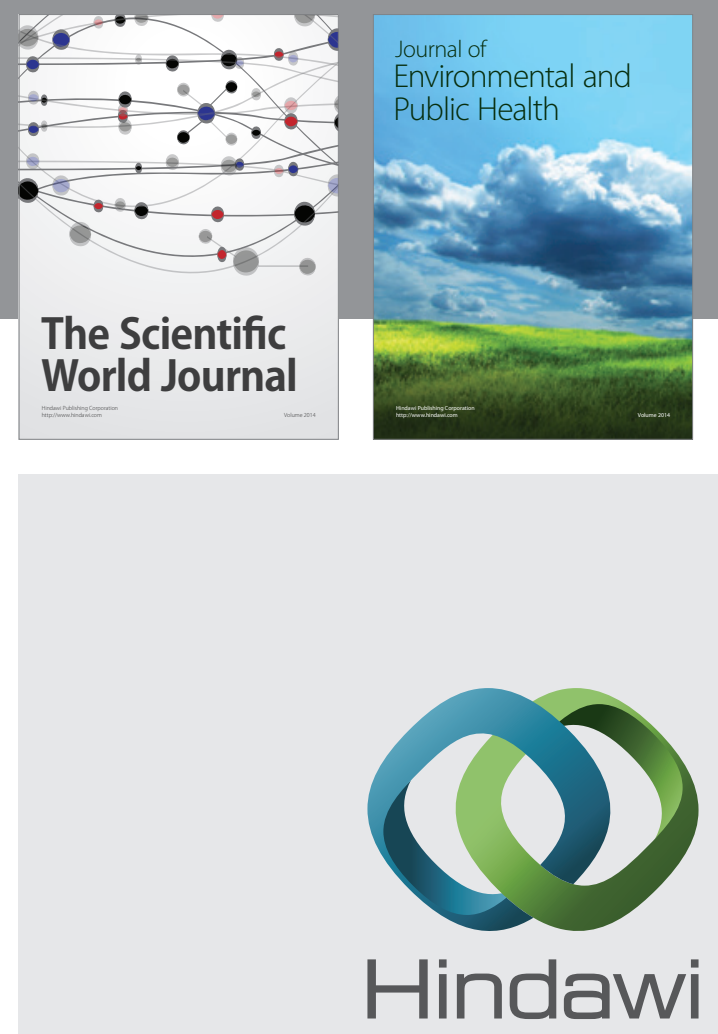

Submit your manuscripts at

http://www.hindawi.com
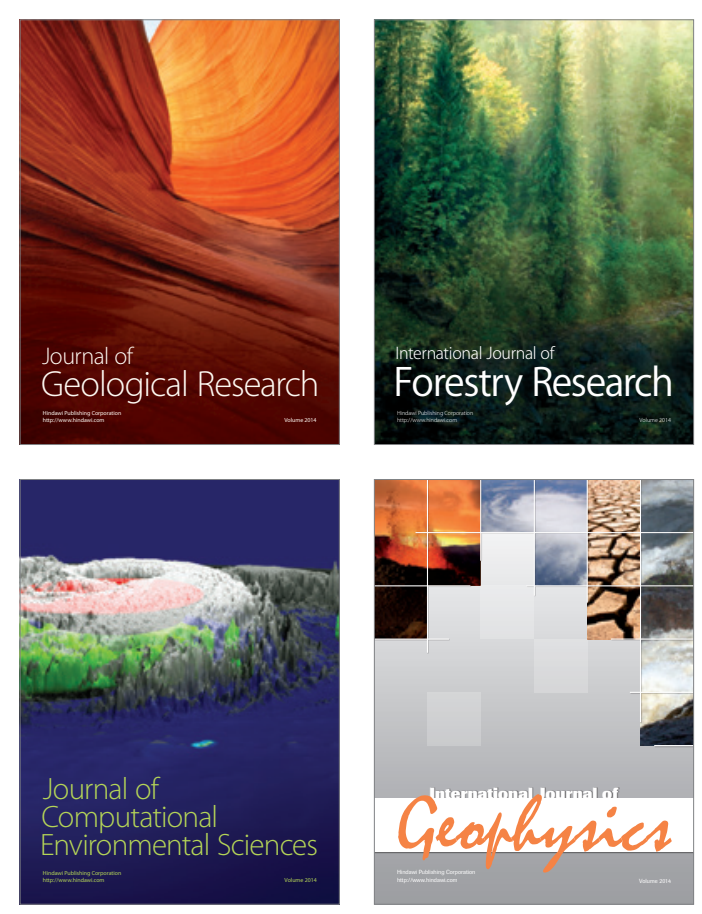
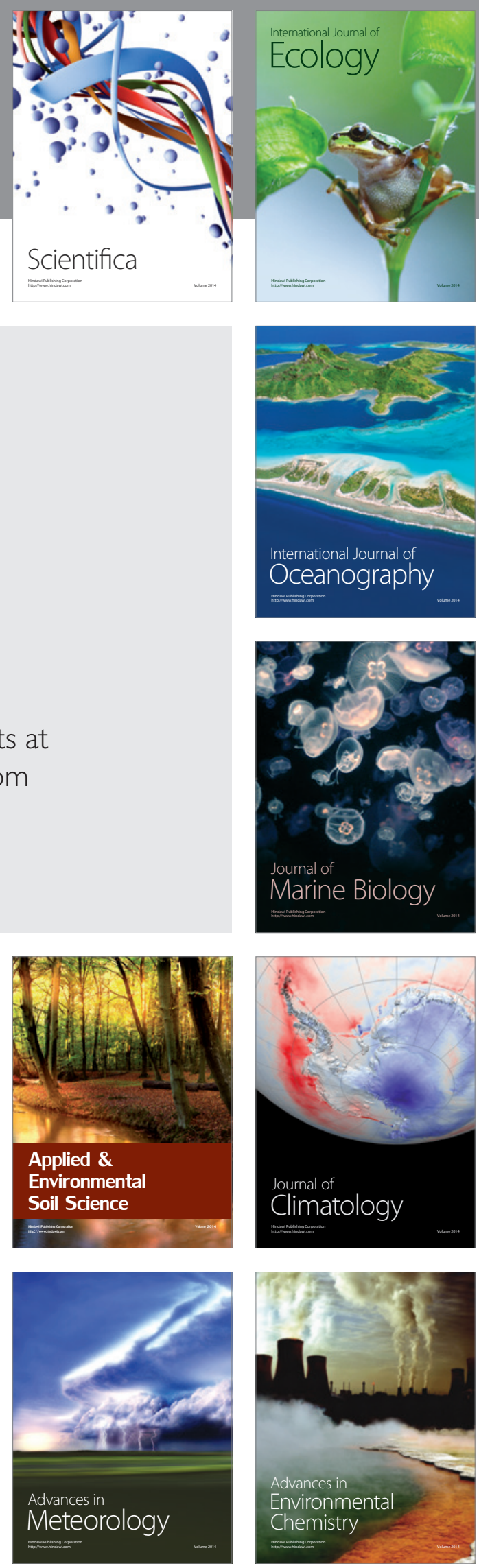